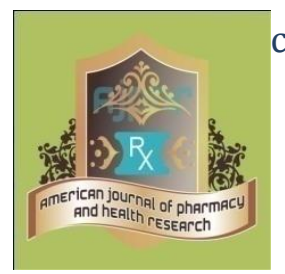

cal industry - article L596 - uniform act - drug - Shareholders' agreements - Carriage

agreement.Review Article
AMERICAN JOURNAL OF PHARMACY AND HEALTH RESEARCH

www.ajphr.com

2018, Volume 6, Issue 01

ISSN: 2321-3647(online)

\title{
A Review on the Assessment of the Efficacy of the Diet in Women with Polycystic Ovary Disorder
}

\author{
P Salome Satya Vani ${ }^{1 *}$, S. Prudvi Raj ${ }^{1}$, P Pallav $^{1}$, C. Ramya $^{1}$, D. Swathi ${ }^{1}$ \\ 1. Pullareddy Institute of Pharmacy, Dommadugu, Sangareddy, Telangana, India ${ }^{1}$
}

\section{ABSTRACT}

The polycystic ovary syndrome (PCOS) is defined as a combination of Hyperandrogenism (hirsutism and acne) and anovulation (oligomenorrhea, infertility, and dysfunctional uterine bleeding), with or without the presence of polycystic ovaries on ultrasound. It represents the main endocrine disorder in the reproductive age, affecting $6 \%-15 \%$ of women in menacme. It is the most common cause of infertility due to anovulation, and the main source of female infertility. PCOS is becoming commoner due to increased awareness and the global increase in the prevalence of overweight and obesity. When in the presence of a menstrual disorder, the diagnosis of PCOS is reached in $30 \%-40 \%$ of patients with primary or secondary amenorrhea and in $80 \%$ of patients with oligomenorrhea. PCOS should be diagnosed and treated early in adolescence due to reproductive, metabolic and oncological complications which may be associated with it. Treatment options include drugs, diet and lifestyle improvement. The optimal approach to dietary management of patients with PCOS gives beneficiary effects. Some studies revealed that PCOS is associated with overweight or obesity; successful weight reduction is the most effective method of restoring normal ovulation and menstruation. Low-carbohydrate diet and sustained regular exercise may help. It has been recommended that a diet in which a significant part of total carbohydrates is obtained from fruit, vegetables and whole grain sources may be helpful.

Keywords: Polycystic Ovary Syndrome, Infertility, Anovulation, Hyperandrogenism, Insulin Resistance.

*Corresponding Author Email: pssalom@gmail.com 
Received 03 January 2018, Accepted 17 January 2018

\section{INTRODUCTION}

The most common endocrine disorder, PCOS is becoming commoner due to increased awareness and the global increase in the prevalence of overweight and obesity. It is a heterogeneous disorder that has been difficult to define because there is no single abnormality or diagnostic test that defines the syndrome. While precise definitions are important for scientific studies, as a working definition the syndrome may be diagnosed if at least two of the following are present:

- Oligomennorhoea or amenorrhoea associated with decreased ovulation. PCOS is the commonest cause of anovulatory infertility.

- Hyperandrogenaemia or clinical features of androgen excess, in the absence of other underlying disease states.

- Abnormal ovarian ultrasound with 12 or more follicles in each ovary each having a diameter of 2-9mm, or increased ovarian volume.

- Increased LH with increased LH/FSH ratio. The diagnosis is more certain with the presence of increasing number of features. Many overweight or obese women have menstrual irregularity, decreased fertility or hirsutism without fulfilling diagnostic criteria for PCOS.

The pathogenesis and management of these is the same as for women with PCOS. Specific treatments for hirsutism and subfertility have substantially improved management of PCOS in recent years but do not generally influence the underlying condition which is largely due to overnutrition and insulin resistance. Even PCOS patients who are not overweight are often insulin resistant, and modest weight loss improves outlook in patients of near normal body weight. The association of PCOS with the abnormalities of metabolic syndrome (central obesity, dyslipidaemia, hypertension and glucose intolerance) is 4 responsible for the documented relationship with type 2 diabetes, cardiovascular disease and hormonally-responsive cancers in later life ${ }^{[1,2]}$. This article reviews our understanding of nutritional aspects of PCOS, and proposes an approach to diet management and nutritional therapy in patients with PCOS. The optimal approach to dietary management of patients with PCOS remains to be defined ${ }^{[3]}$.

\section{Classification}

PCOS affects women of childbearing age without higher prevalence by ethnic groups, but the signs and symptoms may differ by ethnicity. Today, the most widely used tool for diagnosing PCOS are still the "Rotterdam Criteria"; its prevalence is up to five times higher than when defined by the NIH criteria ${ }^{[4] .}$ 
Only a third of patients have the classic form of the syndrome described by Stein and Leventhalin 1935. The concept of PCOS is very broad; it is clinically characterized by the presence of menstrual dysfunction, chronic anovulation and hyperandrogenism ${ }^{[5]}$. The three main consensuses on PCOS defined the criteria for diagnosis which are highlighted below:

The Rotterdam ESHRE/ASRM-Sponsored PCOS Consensus Workshop Group Fertility and Sterility (2003) Presence of 2 out of 3 criteria:

1) Oligoovulation or anovulation;

2) Clinical or biochemical signs of hyperandrogenism;

3) Polycystic ovaries on ultrasound. As defined by the Rotterdam Criteria in 2003, polycystic ovaries have as their concept, the presence of at least one ovary of 12 or more follicles with diameters of 2 - $9 \mathrm{~mm}$ and/or increase the ovarian size > $10 \mathrm{ml}$ (The ESHRE Rotterdam/ASRM, 2004). In addition to these criteria, other medical conditions that can cause chronic anovulation and androgen excess should be excluded, such as:

- Hyperprolactinemia/hyperthyroidism ;

- Congenital adrenal hyperplasia, classical and nonclassical form ;

- Cushing's syndrome; secretory ovarian tumor of adrenal androgens ${ }^{[4]}$

The Thessaloniki ESHRE/ASRM-Sponsored PCOS (2006)

In 2006, The Androgen Excess and PCOS Society (AE-PCOS) published its positioning regarding the diagnosis of polycystic ovary syndrome. According to this association, the androgen excess needs to be present, either by clinical signs, or by biochemical hyperandrogenism. Thus, for diagnosing of the syndrome, two of the following criteria would be necessary:

1) Oligo and/or anovulation and polycystic ovaries on ultrasound;

2) Clinical or laboratory evidence of androgen excess ${ }^{[4][6] .}$

To get to these criteria, they considered the syndrome as an androgen excess disorder and its fundamental characteristics: menstrual or ovulatory dysfunction, hyperandrogenemia, clinical hyperandrogenism and polycystic ovarie. Further, the association pointed out that, the resulting phenotypes from the combination of such characteristics, as a group, but not necessarily individually, have insulin resistance and attendant risk of metabolic abnormalities ${ }^{[4][6] \text {. }}$

The Amsterdam ESHRE/ASRM-Sponsored 3rd PCOS Consensus, 2012 most recently defined presence of 2 out of 3 criteria:

- Menstrual dysfunction and/or polycystic ovary; 
- Hyperandrogenia and/or hyperandrogenism;

- The ultrasound showing a polycystic ovary ${ }^{[7]}$

\section{Epidemiology}

There are few epidemiological studies about the PCOS, mainly on population-based. The vast majority of published studies consist in data from clinical trials, many of them carried out in populations in endocrine care services or infertility clinics, with sample and classification problems, leading to difficulties in generalizability and comparability.

The United States and Europe are leading research into PCOS and more recently, some data were published by authors from outside this axis. The difficulties in classification PCOS and the diagnostic criteria to identify the main phenotypes have been discussed only in the last two decades, having difficulty finding a consensus ${ }^{[8]}$. It is estimated that worldwide, 105 million women between 15 and 49 years of age show PCOS, the same being responsible for $72 \%$ to $82 \%$ of causes of hyperandrogenism ${ }^{[9]}$.

\section{Symptoms}

Symptoms include either excessive or absence of menstruation, Excessive hair growth or Hirsutism which occurs due to presence large no of male hormones, Acne, Drastic weight gain and one of the major symptom i.e. difficulties in conceiving ${ }^{[10-13]}$

\section{Standard Diagnostic Assessment}

\section{A.History-taking}

Specifically needed for menstrual pattern, obesity, hirsutism and the absence of breast development. If obese, the time of onset, progression and problems should be explored. Lifestyle parameters such as diet, exercise and smoking need evaluation, as do the age of onset and progression of hirsutism and/or acne. Any medications used and their effects on acne and hirsutism should also be considered. Family history should explore infertility, menstrual disorders, age of puberty and hirsutism in female relatives ${ }^{[14] \text {. }}$

\section{B. Physical examination}

This includes general body habitus, obesity, body mass index, blood pressure, presence of acne, male pattern of baldness and evidence of acanthosis nigricans. The severity and distribution of hirsutism should be graded clinically. Girls with PCOS with marked hyperandrogenism such as clitoromegaly, deepening of the voice or a masculine body habitus should alert one to the possibility of virilizing adrenal/ovarian tumours or congenital adrenal hyperplasia ${ }^{[15] .}$

\section{Gynecologic ultrasonography}


It looks for small ovarian follicles. According to the Rotterdam criteria, 12 or more small follicles should be seen in an ovary on ultrasound examination. The numerous follicles contribute to the increased size of the ovaries that is 1.5 to 3 times larger than normal ${ }^{[16]}$.

\section{Laboratory tests}

Serum levels of androgens, including androstenedione and testosterone may be elevated. Dehydroepiandrosterone sulfate (DHEA-S) levels above $700-800 \mathrm{mcg} / \mathrm{dL}$ are highly suggestive of adrenal dysfunction. The free testosterone level is thought to be the best measure, with about $60 \%$ of PCOS patients demonstrating high levels [17].

2. The ratio of $\mathrm{LH}$ (Luteinizing hormone) to $\mathrm{FSH}$ (Follicle stimulating hormone) is greater than $1: 1$ (sometimes more than $3: 1$ ), as tested on day 3 of the menstrual cycle ${ }^{[18]}$.

3. Fasting biochemical screen and lipid profile.

4. Two-hours oral glucose tolerance test (GTT) in patients with risk factors (Obesity, family history, history of gestational diabetes) may indicate impaired glucose tolerance (insulin resistance) in patients with $\operatorname{PCOS}^{[19] .}$

5. Fasting insulin level or GTT with insulin levels (also called IGTT): Elevated insulin levels have been helpful to predict response to medication and may indicate patients who will need higher doses of metformin or the use of a second medication to lower insulin levels. A hypoglycemic response in which the two-hour insulin level is higher and the blood sugar lower than fasting is consistent with insulin resistance. A mathematical derivation known as the HOMAI, calculated from the fasting values in glucose and insulin concentrations, allows a direct and moderately accurate measure of insulin sensitivity (glucose-level x insulin-level/22.5) ${ }^{\text {[20]. }}$

\section{E. Differential Diagnosis of PCOS}

Other causes of irregular or absent menstruation and hirsutism, such as hypothyroidism, congenital adrenal hyperplasia (21-hydroxylase deficiency), Cushing's syndrome, hyperprolactinemia, androgen secreting neoplasms and other pituitary or adrenal disorders should be investigated. PCOS has been reported in other insulin-resistant situations such as acromegaly ${ }^{[19] .}$ Management of PCOS Medical treatment of PCOS aims to lowering insulin levels, restore fertility, treat hirsutism or acne, restore regular menstruation and prevent endometrial hyperplasia and endometrial cancer. General interventions that help to reduce weight or insulin resistance can be beneficial for all these aims because they are believed to be the underlying causes ${ }^{[19]}$.

\section{Diet regulation}


Where PCOS is associated with overweight or obesity, successful weight reduction is the most effective method of restoring normal ovulation and menstruation. Low-carbohydrate diet and sustained regular exercise may help. It has been recommended that a diet in which a significant part of total carbohydrates is obtained from fruit, vegetables and whole grain sources may be helpful. Vitamin D deficiency may play a role in the development of the metabolic syndrome because vitamin $\mathrm{D}$ is essential for formation of the hormones of the adrenal cortex. So, treatment of vitamin D deficiency is indicated in the management of PCOS ${ }^{[21] .}$

\section{Medications}

Reducing insulin resistance by improving insulin sensitivity through medications such as metformin and thiazolidinedione have been an obvious approach and initial studies seemed to show effectiveness. The United Kingdom's National Institute for Health and Clinical Excellence recommended in 2004 that women with PCOS and a body mass index above 25 be given metformin when other therapy has failed to produce results ${ }^{[22] .}$

\section{Problems in Current Dietary Pattern}

If we take a look at the eating habits of the majority of the people, it can be clearly observed that there is a remarkably noticeable shift from eating fresh home cooked food to readymade, processed food on a daily basis. This diet lacks fiber, nutrients and minerals and so the amount of fiber intake has reduced drastically, especially in the developed countries. To add to the woes, there is an increased use of preservatives, chemicals, pesticides, chemical fertilizers from the initial stages of farming till the goods are packed and sold in the markets. Abundant use of plastics has also resulted in food and water contamination. In different ways, many chemicals, which are harmful and disrupt endocrine system, are getting into the human system. The general calorie intake has also shot up over the last couple of decades and this factor along with reduction in physical activities is causing the metabolic syndrome which in turn leads to PCOS. Exercise and diet can alter the metabolic syndrome associated with PCOS ${ }^{[23] .}$

\section{Dietary management of polycystic ovary syndrome}

Research into the dietary management of PCOS is lacking, despite the fact that lifestyle modifications including diet, exercise and weight loss have been shown to be beneficial. A reduction in weight of as little as $5 \%$ of total body weight has been shown to reduce insulin levels, improve menstrual function, reduce testosterone levels and improve symptoms of hirsutism and acne ${ }^{[24-40]}$.

Approximately $50 \%$ of women with PCOS are obese and this obesity is associated with a greater degree of insulin resistance, hyperinsulinaemia, lipid abnormalities, hyperandrogenism, hirsutism 
and menstrual irregularities (41 - 46). Furthermore, there is a higher prevalence of abdominal body fat distribution in women with PCOS, even those of a normal body weight, and this increase in visceral fat has been shown to be associated with glucose intolerance and dyslipidaemia $^{[47-48]}$

Most of the studies of dietary intervention in women with PCOS have focused on energy restriction rather than dietary composition per se, yet the weight loss seen in most of these studies has been small in comparison with the outcomes achieved. And while the incidence of insulin resistance is higher in women with PCOS who are obese, and weight loss clearly improves outcomes for these women, not all women with PCOS who have insulin resistance are overweight or obese. Studies have demonstrated a higher incidence of insulin resistance, IGT and type 2 diabetes in women with PCOS of normal weight [49-52], suggesting that dietary management of this condition must go beyond weight loss.

In most of the dietary studies in women with PCOS, improvements in metabolic and reproductive outcomes have been closely related to improvements in insulin sensitivity, suggesting that dietary modification designed to improve insulin resistance may produce benefits greater than those achieved by energy restriction alone.

With the high incidence of insulin resistance and IGT and the increased risk of type 2 diabetes in women with PCOS, research into the effects of diet and exercise on diabetes prevention is highly relevant to this group. The Diabetes Prevention Program achieved a $58 \%$ reduction in risk of progression from IGT to type 2 diabetes with lifestyle modification, with the average weight loss a modest $5.6 \mathrm{~kg}{ }^{\text {[53]. }}$ These results were similar to the Finnish Diabetes Prevention Study, which also achieved a $58 \%$ reduction in risk of diabetes with lifestyle changes including diet and

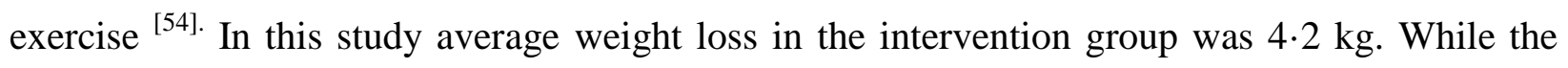
Diabetes Prevention Program and Diabetes Prevention Study included only overweight and obese subjects, the Da Qing Study in China achieved a reduction in the incidence of diabetes with diet and exercise that was equally successful in normal-weight and obese subjects, suggesting that the benefits of diet and exercise were not related only to weight loss ${ }^{[55] \text {. }}$

A recent study found that while the addition of metformin to a hypoenergetic diet improved menstrual function, there was no improvement in insulin sensitivity and hyperinsulinaemia [38]. Similarly, Hoeger et al. (2004) found no benefits on insulin sensitivity or glucose metabolism with the addition of metformin to lifestyle changes, although the combination did result in a greater weight loss and reduction in androgen levels compared with lifestyle changes or metformin alone. 


\section{Effects of dietary-induced weight loss :}

Several studies have demonstrated a beneficial impact of weight loss on insulin resistance and hyperinsulinaemia in PCOS. In a first non-controlled study (24), 20 obese anovulatory women were evaluated, 14 with PCOS and 6 with the hyperandrogenism-insulin resistance-acanthosis Nigerians syndrome, before and after an average of 8 months on a hypocaloric dietary regimen. After a mean weight loss of $9.7 \mathrm{~kg}$ (from $85.9 \pm 13.1$ to $76.1 \pm 14.1$ ), glucose-stimulated insulin concentrations significantly decreased, consistent with an improvement in insulin sensitivity. The beneficial effect of diet-induced weight loss on fasting and glucose-stimulated insulin concentrations was subsequently confirmed by other controlled and non controlled studies [34]. Insulin sensitivity before and after weight loss has also been studied by the use of the euglycaemic hyperinsulinaemic clamp technique ${ }^{[26,32,46]}$

As reported in a recent review, weight reduction also has a potential benefit on lipid abnormalities, such as an increase in HDL-cholesterol and a decrease in triglyceride concentrations ${ }^{[34] .}$ However, data are insufficient and long-term results are not available.

\section{Which diet is best?}

In search of the best diet to improve fertility and hormonal alterations in obese PCOS women, Moran et al. (2003) carried out a short-term study to investigate the effectiveness of a moderately energy restricted low protein-high carbohydrate (15 and 55\% respectively) versus a high protein-low carbohydrate ( 25 and $40 \%$ respectively) diet. The authors found that both diets had a similar effect on body weight loss, glucose and insulin response to a standard meal test, with marginal differences in androgen concentrations in favour of the low protein-high carbohydrate diet. No other studies have investigated the efficacy of other different diets or of a selected manipulation of the macronutrient without energy restriction. Moreover, there are no studies on the potential benefit of short term versus long-term lifestyle manipulation, or on the effect of mild-to-moderate weight loss versus sustained weight loss. Issues for which more detailed data are needed also include the effect of lifestyle intervention in normal-weight PCOS women, whether some differences may exist according to ethnic variability, the effect of previous dietary habits, the effects of dietary manipulation on acne and hirsutism, pregnancy and neonatal outcomes, and, finally, long-term effects on diabetes and cardiovascular diseases.

\section{Foods to AVOID:}

\section{A. High GI (Glycaemic Index) Foods:}

Foods that have a high GI result in a quick rise in blood sugar levels. Insulin levels follow suit to deal with the glucose in the blood stream. Generally, high GI foods have been processed to 
remove fibre and other nutrients so they may be tasty but they are high in calories while lacking in nutrients. ${ }^{[56]}$

Some examples of high GI foods to avoid: white rice, mashed potatoes, rice cakes, muffins and cakes.

\section{B. Dairy:}

We'll get into more detail in a separate blog post, as it's an important and often overlooked issue. Milk leads to a rise in testosterone levels. It contains a protein that limits normal testosterone processing in the body. With testosterone not being managed, testosterone levels just keep rising. As our testosterone levels are already prone to being high, dairy just makes the problem worse $^{\text {[57] }}$

\section{Soy Products:}

When I cut out dairy, I immediately turned to soy. Imagine my dismay when I found that soy has been implicated in delayed ovulation. Not enough studies have been done on the impact of soy on woman with PCOS and soy in small quantities may have little effect. However, I would not recommend soy products to women with PCOS, especially those that are trying to conceive. ${ }^{[58]}$

\section{Bad Fats:}

Saturated, hydrogenated and transfats are all fats that should be avoided. Saturated fats, found in red meat and dairy products, cause an increase in oestrogen production, hinder the absorption of some nutrients and can cause weight gain.[59]

The trans and hydrogenated fats, from cooked oil, margarine and processed foods, increase your risk of heart disease and diabetes, both of which we are already at risk of as a result of our PCOS.

So, cut down on red meat and get rid of the dairy, for all of the reasons also mentioned under the dairy section. Also, avoid those processed, fatty foods.

\section{Foods to INCLUDE:}

\section{A. Green Leafy Vegetables:}

Green, leafy vegetables have the most nutrients per calorie than any other food. They are rich in iron, calcium, potassium, and magnesium, as well as vitamins $\mathrm{K}, \mathrm{C}, \mathrm{E}$, and many of the B vitamins.

Vitamin B in particular plays a vital role in managing PCOS symptoms. This is also worth a further discussion so I will write a separate post for it. Here are just some of the things that Vitamin B is responsible for: sugar and fat metabolism, thyroid function and hormone balance, amongst others. It plays a vital role in the management of PCOS ${ }^{.60-72]}$ 


\section{B. Fruit:}

Fruit is a rich source of fibre, vitamins, minerals and phytonutrients and should be enjoyed as part of a PCOS diet. Many women with PCOS are reluctant to eat fruit or avoid fruit as it can cause a spike in blood sugar levels and therefore insulin.

However, fruit still plays an important role in providing the nutrients we need to combat PCOS. So, try to eat fruit that has a lower GI and have a handful of seeds or nuts with your fruit as protein helps to regulate the sugar spike resulting from fruit.

Fruit with a low GI value include: cherries, plums, grapfruit, apples, pears, apples, dried apricots, grapes, coconut, coconut milk, kiwi fruit, orange juice, prunes. ${ }^{\text {[73-77] }}$

\section{Coloured and White Vegetables}

Brightly coloured vegetables are a rich source of anti-oxidants and should be included in a PCOS diet. Women with PCOS have been found to have a higher rate of oxidative stress. That is, physiological stress is placed on the body when dealing with high numbers of free-radicals. We need antioxidants to combat this oxidative stress. ${ }^{[78-83]}$

\section{Organic, pasture-fed meat}

This may be expensive but it is important that you eat good quality, lean meat if you do eat meat. Grass-fed meat tends to be leaner and contain less hormones than standard meat. Grass-fed is also important because livestock is often fed grain and feed that has been genetically modified or contains pesticides which are unhelpful for hormone balance and PCOS ${ }^{\text {[84-91] }}$

\section{E. Healthy Fats:}

Not all fat is bad and healthy fats are essential for your PCOS diet.

Essential fatty acids are really important for maintaining the cell wall, which allows nutrients in, and toxins out. They are also vital for hormone balance, weight management and fertility.

These healthy fats are found in nuts and seeds, oily fish, avocado and olive oil so be sure to incorporate those into your diet ${ }^{[92-96]}$

\section{F. Supplements:}

Following the diet described above will give you a good chance to get all of the vitamins and minerals you need but many women with PCOS are still lacking in some nutrients.

So, make sure that you take a good multivitamin and mineral supplement. It should contain the following Vitamins and minerals: Vitamin A, D, E, C, B1, B2, B3, B6, B12, folic acid, magnesium, iron, zinc, chromium, selenium and manganese.

This should provide you with a good supplemental basis. Many women with PCOS also take a Vitamin B complex, Vitamin D, chromium, Omega 3 and Ovasitol ${ }^{[97-103]}$ 


\section{CONCLUSION:}

PCOS is a complex condition, with diverse implications that include reproductive, metabolic, and psychological co-morbidities. Its clinical management should focus on lifestyle changes with medical therapy when required, as well as providing patients with support and nutritional education. Body weight loss is associated with beneficial effects on hormones, metabolism and clinical features. Diet modifications along with the treatment are necessary for greater improvement of metabolic and hormonal parameters in women with PCOS.

\section{REFERENCES}

1. Ehrmann DA. Polycystic ovary syndrome.[see comment]. New England Journal of Medicine 2005;352(12):1223-36.

2. Sartor BM, Dickey RP. Polycystic ovarian syndrome and the metabolic syndrome. American Journal of the Medical Sciences 2005;330(6):336-42.

3. Marsh K, Brand-Miller J. The optimal diet for women with polycystic ovary syndrome? British Journal of Nutrition 2005;94(2):154-65.

4. Rotterdam ESHRE/ASRM-Sponsored PCOS Consensus Workshop Group (2004) Revised 2003 Consensus on Diagnostic Criteria and Long Term Health Risks Related to Polycystic Ovary Syndrome PCOS (Review). Human Reproduction, 19, 41-47.

5. Baracat, E.C. and Soares-Junior, J.M. (2007) Ovários policísticos, resistência insulínica e síndrome metabólica. Revista Brasileira de Ginecologia e Obstetrícia, 29, 117-119.

6. (2006) The Thessaloniki ESHRE/ASRM-Sponsored PCOS Consensus Workshop Group.

7. (2012) Consensus on Women'S Health Aspects of Polycystic Ovary Syndrome PCOS: The Amsterdam ESHRE/ ASRM-Sponsored 3rd PCOS Consensus Workshop Group.

8. Ning, N., Balen, A., Brezina, P.R., Leong, M., Shoham, Z., Wallach, E.E. and Zhao, Y. (2013) How to Recognize PCOS: Results of a Web-Based Survey at IVFWorldwide.com. Reproductive Biomedicine, 26, 500-505.

9. Azziz, R., Carmina, E., Dewailly, D., Diamanti-Kandarakis, E., Escobar-Morreale, H.F., Futterweit, W., Janssen, O.E., Legro, R.S., Norman, R.J., Taylor, A.E. and Witchel, S.F.; Androgen Excess Society (2006) Positions Statement: Criteria for Defining Polycystic Ovary Syndrome as a Predominantly Hyperandrogenic Syndrome: An Androgen Excess Society Guideline. The Journal of Clinical Endocrinology \& Metabolism, 91, 4237-4245.

10. Reiter RJ. Melatonin and human reproduction. Ann Med. 1998;30: 103-108. 
11. Wira CR, et al. Innate Immunity in the Human Female Reproductive Tract: Endocrine Regulation of Endogenous Antimicrobial Protection Against HIV and Other Sexually Transmitted Infections. Am J Reprod Immunol. 2011;65: 196-211.

12. Ungerfeld R and Bielli A Seasonal and Social Factors Affecting Reproduction Animal Reproduction in Livestock. UNESCO Press,USA. 2012.

13. Melo MAB, et al. Clinical treatment and assisted reproduction in infertility associated to polycystic ovaries. Reprod Clim. 2000;35: 82-87.

14. Diamanti-Kandarakis E (2010) PCOS in adolescents. Best Pract Res Clin Obstet Gynaecol 24: 173-183.

15. Tharian K, Warner J (2011) Polycystic ovarian syndrome in adolescent girls. Paediatric and Child Health 21: 309-314.

16. Azziz R (2006) Controversy in clinical endocrinology: diagnosis of polycystic ovarian syndrome: the Rotterdam criteria are premature. J Clin Endocrinol Metab 91: 781-785

17. Pasquali R, Gambineri A (2006) Insulin-sensitizing agents in polycystic ovary syndrome. Eur J Endocrinol 154: 763-775.

18. Sharquie KE, Al-Bayatti AA, Al-Ajeel AI, Al-Bahar AJ, Al-Nuaimy AA (2007) Free testosterone, luteinizing hormone/follicle stimulating hormone ratio and pelvic sonography in relation to skin manifestations in patients with polycystic ovary syndrome. Saudi Med J 28: 1039-1043.

19. Teede H, Deeks A, Moran L (2010) Polycystic ovary syndrome: a complex condition with psychological, reproductive and metabolic manifestations that impacts on health across the lifespan. BMC Med 8: 41.

20. Broder-Fingert S, Shah B, Kessler M, Pawelczak M, David R (2009) Evaluation of adolescents for polycystic ovary syndrome in an urban population. J Clin Res Pediatr Endocrinol 1: 188-193.

21. Marsh K, Brand-Miller J (2005) The optimal diet for women with polycystic ovary syndrome? Br J Nutr 94: 154-165.

22. Leeman L, Acharya U (2009) The use of metformin in the management of polycystic ovary syndrome and associated anovulatory infertility: the current evidence. J Obstet Gynaecol 29: 467-472.

23. Barnard RJ, Wen SJ (1994) Exercise and diet in the prevention and control of the metabolic syndrome. Sports Med 18: 218-228. 
24. Pasquali R, Antenucci D, Casimirri F, Venturoli S, Paradisi R, Fabbri R, Balestra V, Melchionda N \& Barbara L (1989) Clinical and hormonal characteristics of obese amenorrheic hyperandrogenic women before and after weight loss. J Clin Endocrinol Metab 68, 173-179.

25. Kiddy DS, Hamilton-Fairley D, Bush A, Short F, Anyaoku V, Reed MJ \& Franks S (1992) Improvement in endocrine and ovarian function during dietary treatment of obese women with polycystic ovary syndrome. Clin Endocrinol 36, 105-111

26. Guzick DS, Wing R, Smith D, Berga SL \& Winters SJ (1994) Endocrine consequences of weight loss in obese, hyperandrogenic, anovulatory women. Fertil Steril 61, 598-604.

27. Andersen P, Seljeflot I, Abdelnoor M, Arnesen H, Dale PO, Lovik A \& Birkeland K (1995) Increased insulin sensitivity and fibrinolytic capacity after dietary intervention in obese women with polycystic ovary syndrome. Metabolism 44, 611-616

28. Clark AM, Ledger W, Galletly C, Tomlinson L, Blaney F, Wang X \& Norman RJ (1995) Weight loss results in significant improvement in pregnancy and ovulation rates in anovulatory obese women. Hum Reprod 10, 2705-2712

29. Crave JC, Fimbel S, Lejeune H, Cugnardey N, Dechaud H \& Pugeat M (1995) Effects of diet and metformin administration on sex hormonebinding globulin, androgens and insulin in hirsute and obese women. J Clin Endocrinol Metab 80, 2057-2062.

30. Holte J, Bergh T, Berne C, Wide L \& Lithell H (1995) Restored insulin sensitivity but persistantly increased early insulin secretion after weight loss in obese women with PCOS. J Clin Endocrinol Metab 80, 2586-2593

31. Jakubowicz DJ \& Nestler JE (1997) 17a-Hydroxyprogesterone responses to leuprolide and serum androgens in obese women with and without polycystic ovary syndrome after dietary weight loss. J Clin Endocrinol Metab 82, 556 -560.

32. Clark AM, Thornley B, Tomlinson L, Galletley C \& Norman RJ (1998) Weight loss in obese infertile women results in improvement in reproductive outcome for all forms of fertility treatment. Hum Reprod 13, 1502-1505.

33. Huber-Buchholz MM, Carey DGP \& Norman RJ (1999) Restoration of reproductive potential by lifestyle modification in obese polycystic ovary syndrome: role of insulin sensitivity and luteinizing hormone. J Clin Endocrinol Metab 84, 1470-1474.

34. Wahrenberg H, Ek I, Reynisdottir S, Carlstro“m K, Bergqvist A \& Arner P (1999) Divergent effects of weight reduction and oral anticonception treatment on adrenergic 
lipolysis regulation in obese women with polycystic ovary syndrome. J Clin Endocrinol Metab 84, 2182- 2187.

35. Pasquali R, Gambineri A, Biscotti D, Vicennati V, Gagliardi L, Colitta D, Fiorini S, Cognigni GE, Filicori M \& Morselli-Labate AM (2000) Effect of long-term treatment with metformin added to hypocaloric diet on body composition, fat distribution, and androgen and insulin levels in abdominally obese women with and without the polycystic ovary syndrome. J Clin Endocrinol Metab 85, 2767-2774.

36. van Dam EW, Roelfsema F, Veldhuis JD, Helmerhorst FM, Frolich M, Meinders AE, Krans HM \& Pijl H (2002) Increase in daily LH secretion in response to short-term calorie restriction in obese women with PCOS. Am J Physiol 282, E865-E872.

37. Crosignani PG, Colombo M, Vegetti W, Somigliana E, Gessati A \& Ragni G (2003) Overweight and obese anovulatory patients with polycystic ovaries: parallel improvements in anthropometric indices, ovarian physiology and fertility rate induced by diet. Hum Reprod 18, 1928-1932.

38. Moran LJ, Noakes M, Clifton PM, Tomlinson L \& Norman RJ (2003) Dietary composition in restoring reproductive and metabolic physiology in overweight women with polycystic ovary syndrome. J Clin Endocrinol Metab 88, 812.

39. Gambineri A, Pelusi C \& Genghini S (2004) Effect of flutamide and metformin administered alone or in combination in dieting obese women polycystic ovary syndrome. Clin Endocrinol 60, 241-249.

40. Stamets K, Taylor DS, Kunselman A, Demers LM, Pelkman CL \& Legro RS (2004) A randomized trial of the effects of two types of short-term hypocaloric diets on weight loss in women with polycystic ovary syndrome. Fertil Steril 81, 630 -637.

41. Pasquali R \& Casimirri F (1993) The impact of obesity on hyperandrogensim and polycystic ovary syndrome in premenopausal women. Clin Endocrinol 39, 1-16.

42. Pasquali R, Casimirri F, Cantobelli S, Labate AM, Venturoli S, Paradisi R \& Zannarini L (1993) Insulin and androgen relationships with abdominal body fat distribution in women with and without hyperandrogensim. Horm Res 39, 179- 187.

43. Pasquali R, Casimirri F, Venturoli S, Antonio M, Morselli L, Reho S, Pezzoli A \& Paradisi R (1994) Body fat distribution has weightindependent effects on clinical, hormonal and metabolic features of women with polycystic ovary syndrome. Metabolism 43, 706-713. 
44. Andersen P, Seljeflot I, Abdelnoor M, Arnesen H, Dale PO, Lovik A \& Birkeland K (1995) Increased insulin sensitivity and fibrinolytic capacity after dietary intervention in obese women with polycystic ovary syndrome. Metabolism 44, 611-616.

45. Ciaraldi TP, Morales AJ, Hickman MG, Odom-Ford R, Olefsky JM \& Yen SS (1997) Cellular insulin resistance in adipocytes from obese polycystic ovary syndrome subjects involves adenosine modulation of insulin sensitivity. J Clin Endocrinol Metab 82, 14211425.

46. Gambineri A, Pelusi C, Vicennati V, Pagotto U \& Pasquali R (2002) Obesity and the polycystic ovary syndrome. Int J Obesity 26, 883-896

47. Kirchengast S \& Huber J (2001) Body composition characteristics and body fat distribution in lean women with polycystic ovary syndrome. Hum Reprod 16, 12251260.

48. Yildirim B, Sabir N \& Kaleli B (2003) Relation of intra-abdominal fat distribution to metabolic disorders in nonobese patients with polycystic ovary syndrome. Fertil Steril 79, 1358-1364.

49. Chang RJ, Nakamura RM, Judd HL \& Kaplan SA (1983) Insulin resistance in nonobese patients with polycystic ovarian disease. J Clin Endocrinol Metab 57, 356-359

50. Jialal I, Naiker P, Reddi K, Moddley J \& Joubert SM (1987) Evidence for insulin resistance in non-obese patients with polycystic ovarian disease. J Clin Endocrinol Metab 64, 1066-1072.

51. Dunaif A, Segal KR, Futterweit W \& Dobrjansky A (1989) Profound peripheral insulin resistance, independent of obesity, in polycystic ovary syndrome. Diabetes 38, 11651174.

52. Fenkci V, Fenkci S, Yilmazer M \& Serteser M (2003) Decreased total antioxidant status and increased oxidative stress in women with polycystic ovary syndrome may contribute to the risk of cardiovascular disease. Fetil Steril 80, 123-127.

53. Diabetes Prevention Program Research Group (2002) Reduction in the incidence of type 2 diabetes with lifestyle intervention or metformin. N Engl J Med 346, 393-403.

54. Tuomilehto J, Lindstrom J, Eriksson JG, et al. (2001) Prevention of type 2 diabetes by changes in lifestyle among subjects with impaired glucose tolerance. N Engl J Med 344, $1343-1350$ 
55. Pan XR, Li GW, Hu YH, Wang JX, Yang WY, An ZX, et al. (1997) Effects of diet and exercise in preventing NIDDM in people with impaired glucose tolerance. The Da Qing IGT and Diabetes Study. Diabetes Care 20, 537-544

56. Salomaa V, Ahola I, Tuomilehto J, Aro A, Pietinen P, Korhonen HJ \& Penttila I (1990) Fatty acid composition of serum cholesterol esters in different degree of glucose intolerance. Metabolism 39, 1285-1291.

57. Wijeyarante CN, Nirantharakumar K, Balen AH, Barth JH, Sheriff R \& Belchetz PE (2004) Plasma homocysteine in polycystic ovary syndrome: does it correlate with insulin resistance and ethnicity? Clin Endocrinol 60, 560-567.

58. Skov AR, Toubro S, Ronn B, Holm L \& Astrup A (1999) Randomized trial on protein vs carbohydrate in ad libitum fat reduced diet for the treatment of obesity. Int $\mathbf{J}$ Obes 23 , 528-536.

59. Paolisso G, Tataranni PA, Foley FE, Bogardus C, Howard BV \& Ravussin E (1995) A high concentration of fasting plasma non-esterified fatty acids is a risk factor for the development of NIDDM. Diabetologia 38, 1213-1217.

60. Dunaif A, Thomas A. Current concepts in the polycystic ovary syndrome. Annu Rev Med. 2001;52:401-419.

61. Barth JH, Clark S. Acne and hirsuties in teenagers. Best Pract Res Clin Obstet Gynaecol. 2003;17:131-148.

62. Conway GS, Honour JW, Jacobs HS. Heterogeneity of the polycystic ovary syndrome: clinical, endocrine and ultrasound features in 556 patients. Clin Endocrinol (Oxf) 1989;30:459-470.

63. Expert Panel on Detection, Evaluation, and Treatment of High Blood Cholesterol in Adults. Executive Summary of The Third Report of The National Cholesterol Education Program (NCEP) Expert Panel on Detection, Evaluation, and Treatment of High Blood Cholesterol in Adults (Adult Treatment Panel III) JAMA. 2001;285:2486-2497.

64. Pasquali R, Casimirri F. The impact of obesity on hyperandrogenism and polycystic ovary syndrome in premenopausal women. Clin Endocrinol (Oxf) 1993;39:1-16.

65. Azziz R, Dewailly D, Owerbach D. Clinical review 56: Nonclassic adrenal hyperplasia: current concepts. J Clin Endocrinol Metab. 1994;78:810-815.

66. Yokoyama H, Emoto M, Fujiwara S, Motoyama K, Morioka T, Komatsu M, Tahara H, Shoji T, Okuno Y, Nishizawa Y. Quantitative insulin sensitivity check index and the 
reciprocal index of homeostasis model assessment in normal range weight and moderately obese type 2 diabetic patients. Diabetes Care. 2003;26:2426-2432.

67. Silfen ME, Manibo AM, McMahon DJ, Levine LS, Murphy AR, Oberfield SE. Comparison of simple measures of insulin sensitivity in young girls with premature adrenarche: the fasting glucose to insulin ratio may be a simple and useful measure. $\mathrm{J}$ Clin Endocrinol Metab. 2001;86:2863-2868.

68. Legro RS, Finegood D, Dunaif A. A fasting glucose to insulin ratio is a useful measure of insulin sensitivity in women with polycystic ovary syndrome. J Clin Endocrinol Metab. 1998;83:2694-2698.

69. Ducluzeau PH, Cousin P, Malvoisin E, Bornet H, Vidal H, Laville M, Pugeat M. Glucose-to-insulin ratio rather than sex hormone-binding globulin and adiponectin levels is the best predictor of insulin resistance in nonobese women with polycystic ovary syndrome. J Clin Endocrinol Metab. 2003;88:3626-3631.

70. Carnevale Schianca GP, Rossi A, Sainaghi PP, Maduli E, Bartoli E. The significance of impaired fasting glucose versus impaired glucose tolerance: importance of insulin secretion and resistance. Diabetes Care. 2003;26:1333-1337.

71. Rosner W. An extraordinarily inaccurate assay for free testosterone is still with us. J Clin Endocrinol Metab. 2001;86:2903.

72. Derksen J, Nagesser SK, Meinders AE, Haak HR, van de Velde CJ. Identification of virilizing adrenal tumors in hirsute women. N Engl J Med. 1994;331:968-973.

73. Luciano AA, Chapler FK, Sherman BM. Hyperprolactinemia in polycystic ovary syndrome. Fertil Steril. 1984;41:719-725.

74. Franks S. Polycystic ovary syndrome: a changing perspective. Clin Endocrinol (Oxf) 1989;31:87-120.

75. Rittmaster R. Treating hirsutism. Endocrinologist. 1993;3:211-218.

76. Bracero N, Zacur HA. Polycystic ovary syndrome and hyperprolactinemia. Obstet Gynecol Clin North Am. 2001;28:77-84.

77. Franks S. Polycystic ovary syndrome. N Engl J Med. 1995;333:853-861.

78. Yanovski JA, Cutler GB, Jr, Chrousos GP, Nieman LK. The dexamethasone-suppressed corticotropin-releasing hormone stimulation test differentiates mild Cushing's disease from normal physiology. J Clin Endocrinol Metab. 1998;83:348-352

79. Polson DW, Adams J, Wadsworth J, Franks S. Polycystic ovaries—a common finding in normal women. Lancet. 1988;1:870-872. 
80. Adams J, Franks S, Polson DW, Mason HD, Abdulwahid N, Tucker M, Morris DV, Price J, Jacobs HS. Multifollicular ovaries: clinical and endocrine features and response to pulsatile gonadotropin releasing hormone. Lancet. 1985;2:1375-1379.

81. Jonard S, Robert Y, Cortet-Rudelli C, Pigny P, Decanter C, Dewailly D. Ultrasound examination of polycystic ovaries: is it worth counting the follicles? Hum Reprod. 2003;18:598-603.

82. Homburg R. What is polycystic ovarian syndrome? A proposal for a consensus on the definition and diagnosis of polycystic ovarian syndrome. Hum Reprod. 2002;17:24952499.

83. Coulam CB, Annegers JF, Kranz JS. Chronic anovulation syndrome and associated neoplasia. Obstet Gynecol. 1983;61:403-407.

84. Diamanti-Kandarakis E, Baillargeon JP, Iuorno MJ, Jakubowicz DJ, Nestler JE. A modern medical quandary: polycystic ovary syndrome, insulin resistance, and oral contraceptive pills. J Clin Endocrinol Metab. 2003;88:1927-1932.

85. Kiddy DS, Hamilton-Fairley D, Bush A, Short F, Anyaoku V, Reed MJ, Franks S. Improvement in endocrine and ovarian function during dietary treatment of obese women with polycystic ovary syndrome. Clin Endocrinol (Oxf) 1992;36:105-111.

86. Nestler JE, Jakubowicz DJ, Evans WS, Pasquali R. Effects of metformin on spontaneous and clomiphene-induced ovulation in the polycystic ovary syndrome. $\mathrm{N}$ Engl $\mathrm{J}$ Med. 1998;338:1876-1880.

87. Pirwany IR, Yates RW, Cameron IT, Fleming R. Effects of the insulin sensitizing drug metformin on ovarian function, follicular growth and ovulation rate in obese women with oligomenorrhoea. Hum Reprod. 1999;14:2963-2968.

88. Heard MJ, Pierce A, Carson SA, Buster JE. Pregnancies following use of metformin for ovulation induction in patients with polycystic ovary syndrome. Fertil Steril. 2002;77:669-673.

89. Glueck CJ, Wang P, Fontaine R, Tracy T, Sieve-Smith L. Metformin-induced resumption of normal menses in 39 of $43(91 \%)$ previously amenorrheic women with the polycystic ovary syndrome. Metabolism. 1999;48:511-519.

90. Vrbikova J, Hill M, Starka L, Vondra K. Prediction of the effect of metformin treatment in patients with polycystic ovary syndrome. Gynecol Obstet Invest. 2002;53:100-104.

91. Moghetti P, Castello R, Negri C, Tosi F, Perrone F, Caputo M, Zanolin E, Muggeo M. Metformin effects on clinical features, endocrine and metabolic profiles, and insulin 
sensitivity in polycystic ovary syndrome: a randomized, double-blind, placebo-controlled 6-month trial, followed by open, long-term clinical evaluation. J Clin Endocrinol Metab. 2000;85:139-146.

92. Morin-Papunen L, Vauhkonen I, Koivunen R, Ruokonen A, Martikainen H, Tapanainen JS. Metformin versus ethinyl estradiol-cyproterone acetate in the treatment of nonobese women with polycystic ovary syndrome: a randomized study. J Clin Endocrinol Metab. 2003;88:148-156.

93. Wiegratz I, Kutschera E, Lee JH, Moore C, Mellinger U, Winkler UH, Kuhl H. Effect of four different oral contraceptives on various sex hormones and serum-binding globulins. Contraception. 2003;67:25-32.

94. Harborne L, Fleming R, Lyall H, Norman J, Sattar N. Descriptive review of the evidence for the use of metformin in polycystic ovary syndrome. Lancet. 2003;361:1894-1901.

95. Breitkopf DM, Rosen MP, Young SL, Nagamani M. Efficacy of second versus third generation oral contraceptives in the treatment of hirsutism. Contraception. 2003;67:349353.

96. Hancock KW, Levell MJ. The use of oestrogen-progestogen preparations in the treatment of hirsutism in the female. J Obstet Gynaecol Br Commonw. 1974;81:804-811.

97. Morin-Papunen LC, Koivunen RM, Ruokonen A, Martikainen HK. Metformin therapy improves the menstrual pattern with minimal endocrine and metabolic effects in women with polycystic ovary syndrome. Fertil Steril. 1998;69:691-696.

98. Kelly CJ, Gordon D. The effect of metformin on hirsutism in polycystic ovary syndrome. Eur J Endocrinol. 2002;147:217-221.

99. Pasquali R, Gambineri A, Biscotti D, Vicennati V, Gagliardi L, Colitta D, Fiorini S, Cognigni GE, Filicori M, Morselli-Labate AM. Effect of long-term treatment with metformin added to hypocaloric diet on body composition, fat distribution, and androgen and insulin levels in abdominally obese women with and without the polycystic ovary syndrome. J Clin Endocrinol Metab. 2000;85:2767-2774.

100. Azziz R, Ehrmann D, Legro RS, Whitcomb RW, Hanley R, Fereshetian AG, O'Keefe M, Ghazzi MN PCOS/Troglitazone Study Group. Troglitazone improves ovulation and hirsutism in the polycystic ovary syndrome: a multicenter, double blind, placebo-controlled trial. J Clin Endocrinol Metab. 2001;86:1626-1632. 
101. 101.Eil C, Edelson SK. The use of human skin fibroblasts to obtain potency estimates of drug binding to androgen receptors. J Clin Endocrinol Metab. 1984;59:5155.

102. Moghetti P, Tosi F, Tosti A, Negri C, Misciali C, Perrone F, Caputo M, Muggeo M, Castello R. Comparison of spironolactone, flutamide, and finasteride efficacy in the treatment of hirsutism: a randomized, double blind, placebo-controlled trial. J Clin Endocrinol Metab. 2000;85:89-94.

103. Lumachi F, Rondinone R. Use of cyproterone acetate, finasteride, and spironolactone to treat idiopathic hirsutism. Fertil Steril. 2003;79:942-946. 